\title{
IMPORTÂNCIA DA REATIVIDADE DO CALCÁRIO SOBRE A PRODUÇÃO E ALGUMAS CARACTERÍSTICAS DA CULTURA DA SOJA
}

\author{
P.A. BELLINGIERI ; E.C.A. SOUZA²; J.C. ALCARDE ${ }^{3}$; H.W. SHIKASHO
}

\begin{abstract}
RESUMO: $O$ experimento foi conduzido num latossolo vermelho escuro, textura média, localizado em Jaboticabal-SP, para se estudar o efeito de dois calcários (dolomítico e dolomítico calcinado), com quatro graus de finuras $\left(F_{1}=>2 \mathrm{~mm} ; F_{2}=2-0,84 \mathrm{~mm} ; F_{3}=0,84-0,30 \mathrm{~mm}\right.$ e $\left.F_{4}=<0,30 \mathrm{~mm}\right)$, sobre propriedades químicas desse solo durante dois anos agrícolas (1988/89 e 89/90) e em características agronômicas da soja cv. IAC-8. Concluiu-se que: no $1^{\circ}$ ano agrícola $(88 / 89)$ o calcário calcinado foi mais reativo, bem como as granulometrias mais finas, sendo que a produção de grãos aumentou em $14 \%$; no $2^{\circ}$ ano (89/90), os calcários e as finuras tenderam a igualar seus efeitos e a produção de grãos não foi alterada; para as análises foliares e de grãos, somente houve efeito para $\mathrm{o} \mathrm{Mg}$.
\end{abstract}

Descritores: calcáreo, tamanho de partícula, soja, reatividade.

\section{EFFECT OF LIMESTONE REACTIVITY ON SOYBEAN CROP CHARACTERISTICS AND YIELD}

ABSTRACT: This experiment was conducted on a dark-red latosol, medium textured, Jaboticabal-SP, Brazil. The main objective was to study the effect of two liming materials (dolomitic and calcined-dolimitic), with four grades of particle size $\left(F_{1}=>2 \mathrm{~mm} ; F_{2}=2-0,84 \mathrm{~mm} ; F_{3}=0,84-0,30 \mathrm{~mm}\right.$ and $\left.F_{4}=<0,30 \mathrm{~mm}\right)$ on the chemical properties of the soil, and on several characteristics of soybean $\mathrm{cv}$ IAC-8, evaluated during two croping seasons (1988/89 and 1989/90). During the first year the calcined-dolomitic limestone and the materials with smaller particles were more active and the yield of grain increased 14 percent. For the second croping season (1989/90) the effects of the liming materials were similar and grain productions were not affected by the treatments $(P>$ $0.05)$. Only the contents of $\mathrm{Mg}$ in the leaves and grains differed among treatments.

Key Words: limestones, particle size, soybean, reactivity.

\section{INTRODUÇÃO}

A experiência tem mostrado que solos ácidos são limitantes à capacidade produtiva da soja. De modo geral, a correção da acidez através da calagem, pode chegar a dobrar a produção de grãos.

Os calcários, materiais mais comumente usados na correção da acidez, variam geralmente quanto às características mineralógicas, composição química $\mathrm{e}$ granulométricas que conjuntamente determinam a capacidade total de neutralização de acidez do solo.
Dentre as características relacionadas com a qualidade dos corretivos da acidez, apenas duas tem sido consideradas: o teor de neutralizantes e a granulometria. $\mathrm{Na}$ avaliação desses produtos, no que tange ao aspecto granulometria, a mesma tem sido feita em termos de capacidade de reação no solo (por períodos curtos de tempo), desconsiderando-se o efeito residual. Em vista disso, a reatividade apresenta apenas uma relação parcial com a qualidade, não devendo refletir satisfatoriamente na eficiência de um corretivo.

\footnotetext{
' Professor Adjunto do Departamento de Tecnologia - Faculdade de Ciências Agrárias e Veterinárias, UNESP. Jaboticabal-SP.

${ }^{2}$ Professor Titular do Departamento de Solos e Adubos - Faculdade de Ciências Agrárias e Veterinárias, UNESP, Jaboticabal-SP.

${ }^{3}$ Professor Associado - Departamento de Química - ESALQ, USP - PIRACICACA-SP

${ }^{4}$ Ex-estagiário do Departamento de Tecnologia. Faculdade de Ciências Agrárias e Veterinárias/UNESP. Jaboticabal
} 
MEYER \& VOLK (1952), trabalhando com soja e alfafa em casa de vegetação, observaram que a fração de calcário retida entre as peneiras 4-8 mesh, tinha um pouco ou nenhum valor como material corretivo; observaram ainda, que a fração retida entre 20-30 mesh de abertura pode tornar-se eficiente em períodos mais longos de tempo. Concluíram que, para o calćrio agrícola ter eficiência após um ano da aplicação, boa parte dele deveria ser suficientemente fino para atravessar a peneira de $\mathbf{4 0}$ mesh.

Por outro lado, HOYERT \& AXLEY (1952) observaram que um calcário com partículas grosseiras (20-40 mesh), mas com material fino suficiente para promover aproximadamente o mesmo efeito sobre o valor $\mathrm{pH}$ do solo que aquele que passa por malha de 100 mesh, poderia ser superior ao último, já que persiste no solo por um período maior. Os autores comprovaram ainda, que a quantidade de corretivo aplicado, tem um efeito maior sobre o valor do $\mathrm{pH}$, que a granulometria.

SHAW \& ROBINSON (1960), estudando a eficiência de calcários de diferentes granulometrias em lisímetros, concluiram que aqueles corretivos com grau de finura menor que 60 mesh dissolviam-se em um ano e aqueles que passavam em peneira de 30 mesh dissolviam-se em apenas 2 anos. Os calcários mais grosseiros (8 mesh) levavam de 3 até 4 anos para se dissolverem. Ainda, nesse estudo, eles apontaram uma igualdade de eficiência entre os calcários calcítico e dolomítico, quando o dolomítico era duas vezes mais fino.

TEDESCO \& ANGHINONI (1980), mostraram que com frações mais finas (partículas que passavam na peneira de 200 malhas por polegada), obtiveram o máximo valor pH obtido pela aplicação, já na segunda semana após a aplicação do corretivo, enquanto que para as partículas mais grossas (10-20 mesh) esse valor máximo do $\mathrm{pH}$ obtido, somente foi alcançado 107 semanas (2 anos) após a aplicação do corretivo.

SOUZA \& NEPTUNE (1979) estudando o efeito da aplicação de calcário com três granulometrias, verificaram aumentos na produção de soja, com a redução na finura do calćrio. Para os autores, isso se deve a maior solubilidade do material, ocorrida em função da menor granulometria. Por outro lado, quando analisaram o efeito residual do calcário, constataram maiores efeitos para o material de granulometria maior e para reatividade, aquele de menor granulometria, que já havia apresentado boa reatividade no primeiro ano de cultivo.
BELLINGIERI (1983) trabalhando com dois tipos de calcário: sedimentar e metamórfico, em trés solos, com diferentes propriedades físicas e químicas, verificou que na reatividade dos calcários, o mais importante $\varepsilon$ a granulometria, independentemente da origem da rocha calcária.

Em vista da caréncia de pesquisas no Brasil sobre esse assunto, torna-se evidente a necessidade de estudos sobre a eficiência das fraçōes granulometricas de calcários em condições de campo.

$O$ objetivo do presente trabalho foi verificar, em condiçōes de campo, a eficiencia de quatro frações granulométricas de 2 tipos de corretivos agrícolas aplicados num latossolo vermelho escuro, textura média, cultivado com soja, em dois anos agrícolas consecutivos (1988/89 e 89/90).

\section{MATERIAL E METODOS}

Utilizou-se de dois tipos de calcários: o dolomítico com $28 \%$ de $\mathrm{CaO}, 14 \%$ de $\mathrm{MgO}$ e PRNT = $78 \%$ e o dolomítico calcinado, com $40 \%$ de $\mathrm{CaO}, 20 \%$ de $\mathrm{MgO}$ e PRNT $=104 \%$, ambos fomecidos em quatro frações granulométricas: $F_{1}=>2 \mathrm{~mm} ; F_{2}=2$ $0,84 \mathrm{~mm} ; F_{3}=0,84-0,30 \mathrm{~mm} \mathrm{e}_{4}=<0,30 \mathrm{~mm}$, as quais foram obtidas da indústria, após o peneiramento do calcário comercialmente moído. As doses aplicadas foram calculadas para elevar a saturação por bases a $70 \%$, estabelecendo-se para cada finura como fator de cálculo o valor do PN (poder neutralizante). A aplicação foi feita no ano agrícola de 1988/89.

O cultivar semeado de soja foi IAC-8. O solo utilizado foi o latossolo vermelho escuro, textura média, com as seguintes características químicas: $\mathbf{P}$ resina $=13 \mathrm{ug} / \mathrm{cm}^{3} ; \mathrm{M} .0 .=1,9 \% ; \mathrm{pH}\left(\mathrm{CaCl}_{2} \mathbf{0 , 0 1 \mathrm { M } )}\right.$ $=4,5 ; \mathrm{K}=0,05 ; \mathrm{Ca}=1,0 ; \mathrm{Mg}=0,3$ e $\mathrm{H}+\mathrm{Al}=$ 3,4 todos em meq $/ 100 \mathrm{~cm}^{3}, \mathrm{~V} \%=28$. O delineamento experimental foi em blocos casualizados, num esquema fatorial $2 \times 4$ ( 2 corretivos $\times 4$ granulometrias) e com um tratamento adicional (testemunha) e 4 repetições. Os calcários foram aplicados em 14.10 .88 e a semeadura realizada dia 06.12.88, usando-se uma adubação de 230 $\mathrm{kg} / \mathrm{ha}$ da formula 2-30-10. No $2^{\circ}$ ano agrícola (89/90) a semeadura foi feita em 20.12 .89 e a adubação recebida igual a do ano anterior.

Foram realizadas quatro amaostragens de solo, de $0-20 \mathrm{~cm}: 111,220,540$ e 730 dias, após a calagem, Também foram feitas duas amostragens de folhas, no início do florescimento da cultura. Os dados das colheitas de grãos foram transformados em $\mathrm{kg} / \mathrm{ha}$. 
QUADRO 1 - Valores médios obtidos para as diversas características analisadas no solo com os respectivos testes F para a análise de variância e testes de Tukey para comparações múltiplas (1 amostragem $0-20 \mathrm{~cm}$, 111 dias após a aplicação dos corretivos).

\begin{tabular}{|c|c|c|c|c|c|c|c|c|c|}
\hline & \multirow{2}{*}{$\underset{\mu \mathrm{g} / \mathrm{ml}}{\mathrm{P}}$} & \multirow{2}{*}{ M.O. } & \multirow{2}{*}{$\begin{array}{c}\mathrm{pH} \\
\mathrm{CaCl}_{2} \\
\mathbf{0 , 0 1 \mathrm { m }}\end{array}$} & $\mathrm{Ca}$ & $\mathbf{M g}$ & $\mathbf{H}+\mathbf{A l}$ & SB & $\mathbf{T}$ & \multirow{2}{*}{$\begin{array}{l}\mathrm{V} \\
\%\end{array}$} \\
\hline & & & & \multicolumn{5}{|c|}{$\mathrm{meq} / 100 \mathrm{~cm}^{3}$} & \\
\hline Dolomítico & $22,25 b$ & 2,01 & $4,80 \mathrm{~b}$ & $1,27 \mathrm{~b}$ & $0,68 b$ & $3,12 a$ & $2,07 b$ & 5,50 & 39,50 \\
\hline $\begin{array}{l}\text { Dolomítico } \\
\text { Calcinado }\end{array}$ & $26,06 a$ & 2,02 & $5,10 \mathrm{a}$ & $1,53 \mathrm{a}$ & $1,02 a$ & $2,65 \mathrm{~b}$ & $2,59 \mathrm{a}$ & 5,41 & $49,94 a$ \\
\hline Teste F & $7,55^{*}$ & 0,04 & $25,41 *$ & $4,53 *$ & $24,24^{*}$ & $21,95 * *$ & $13,67 * *$ & 0,08 & $25,45 * *$ \\
\hline D.M.S. & 2,05 & 0,13 & 0,12 & 0,25 & 0,14 & 0,21 & 0,05 & 0,64 & 4,25 \\
\hline \multicolumn{10}{|l|}{ Frações } \\
\hline $\mathbf{F}_{1}$ & 25,88 & 2,11 & $4,7 b$ & $1,11 \mathrm{~b}$ & $0,70 \mathrm{~b}$ & $3,26 a$ & $1,99 b$ & 5,25 & $37,25 \mathrm{~b}$ \\
\hline$F^{2}$ & 20,63 & 2,01 & $4,80 \mathrm{~b}$ & $1,41 \mathrm{ab}$ & $0,75 b$ & $3,05 \mathrm{a}$ & $2,26 a b$ & 5,00 & $42,50 \mathrm{ab}$ \\
\hline$F^{3}$ & 24,63 & 1,96 & $5,10 \mathrm{a}$ & $1,61 \mathrm{a}$ & $1,04 \mathrm{a}$ & $2,56 b$ & $2,77 \mathrm{a}$ & 5,46 & $50,25 a$ \\
\hline$F^{4}$ & 25,50 & 1,06 & $5,10 \mathrm{a}$ & $1,45 \mathrm{ab}$ & $0,91 \mathrm{ab}$ & $2,66 \mathrm{~b}$ & $2,50 \mathrm{ab}$ & 5,79 & 48,88 \\
\hline Teste F & 3,07 & 1,23 & $10,09 * *$ & 3,00 & $5,08 * *$ & $10,76 * *$ & $3,94 *$ & 0,61 & $38,46 * *$ \\
\hline D.M.S. & 5,37 & 0,25 & 0,23 & 0,47 & 0,27 & 0,39 & 0,66 & 1,21 & 8,01 \\
\hline Testemunha & 19,50 & 1,90 & 4,55 & 0,90 & 0,50 & 3,80 & 1,53 & 4,83 & 32,25 \\
\hline $\begin{array}{l}\text { Teste FT } \\
x \text { demais }\end{array}$ & $5,01 *$ & 1,38 & $20,08 * *$ & $7,57 * *$ & $11,59 * *$ & $37,22 * *$ & $11,18 * *$ & 1,75 & $16,14^{* *}$ \\
\hline $\begin{array}{l}\text { Teste } P p / \\
\text { int } C \times F\end{array}$ & 0,09 & 1,78 & 0,32 & 3,72 & 0,72 & 1,40 & 1,26 & 1,26 & 0,38 \\
\hline
\end{tabular}

Médias com letras iguais não diferem pelo teste de Tukey a $5 \%$

* = significativo a $5 \%$

$* *$ = significativo a $1 \%$

Nas análises de solo foram determinados os tcores de M.O., P, K, Ca, $\mathrm{Mg}$ e $\mathrm{H}+\mathrm{Al}$ e também os valores $\mathrm{pH}$, sendo calculados os valores de $\mathrm{V} \%$, segundo metodologia citada por FERREIRA et al. (1990); nas folhas e grãos determinou-se os teores de $\mathrm{N}, \mathrm{P}, \mathrm{K}, \mathrm{Ca}, \mathrm{Mg}, \mathrm{Cu}, \mathrm{Fe}, \mathrm{Mn}$ e $\mathrm{Zn}$, sendo empregada a metodologia preconizada por BATAGLIA et al. (1983).

\section{RESULTADOS E DISCUSSÃo}

Os dados referentes à $1^{\text {a }}$ amostragem de solo, encontram-se no Quadro 01, pelos quais nota-se o efeito positivo dos calcários sobre os teores de $\mathrm{P}, \mathrm{Ca} \mathbf{e ~} \mathrm{Mg}$, bem como para os valores de $\mathrm{pH}, \mathrm{H}+\mathrm{Al} \mathrm{e} \mathrm{V \% ,} \mathrm{e,}$ dentre esses, o calcinado foi o melhor. Para finuras, as mais finas foram as que mais reagiram, elevando, principalmente, os valores de saturação por bases. Por uma análise global, os melhores efeitos foram: $F_{2}=F_{3}$ $=F_{4}$. Deve-se observar que a saturação por bases chegou a $49 \%$, bem abaixo de $70 \%$, e isso se deve à baixa reatividade dos calcários e das finuras nesses primeiros 111 dias após a calagem.

No Quadro 02, nota-se, que 220 dias após a calagem, os efeitos dos corretivos são ainda mais marcantes, como também a melhor reatividade do dolomítico calcinado. Nessa $2^{\mathrm{a}}$ amostragem, os graus de finura somente afetaram $V \%$, sendo os melhores efeitos obtidos para $F_{2}, F_{3}$ e $F_{4}$. Por esse dado, concluiu-se que a granulometria mais grosseira(2$0,84 \mathrm{~mm}$ ), após um período maior de tempo, torna-se maior que a $F_{1}(>2 \mathrm{~mm})$, pois na $1^{\mathrm{a}}$ amostragem, $F_{1}$ não diferiu estatisticamente de $F_{2}$.

No Quadro 03 estão representados os dados da $3^{\text {a }}$ amostragem, aos 540 dias após a calagem. De uma maneira geral o efeito dos dois calcários se igualaram 
QUADRO 2 - Valores médios obtidos para as diversas características analisadas no solo com os respectivos testes $F$ para a análise de variância e testes de Tukey para comparações múltiplas ( $2^{\text {a }}$ amostragem $0-20 \mathrm{~cm}$, 220 dias após a aplicação dos corretivos).

\begin{tabular}{|c|c|c|c|c|c|c|c|c|c|c|}
\hline \multirow[t]{2}{*}{ Calcários } & \multirow{2}{*}{$\underset{\mu \mathrm{g} / \mathrm{ml}}{\mathbf{P}}$} & \multirow{2}{*}{$\begin{array}{c}\text { M.O. } \\
\%\end{array}$} & \multirow{2}{*}{$\begin{array}{c}\mathbf{p H} \\
\mathrm{CaCl}_{2} \\
0,01 \mathrm{~m}\end{array}$} & $\mathbf{K}$ & $\mathrm{Ca}$ & $\mathbf{M g}$ & $\mathbf{H}+\mathbf{A l}$ & SB & $\mathbf{T}$ & $\mathbf{v}$ \\
\hline & & & & \multicolumn{6}{|c|}{$\mathrm{meq} / 100 \mathrm{~cm}^{3}$} & $\%$ \\
\hline Dolomítico & 19,44 & 1,61 & $4,76 b$ & 0,09 & $1,14 b$ & $0,55 b$ & $2,72 a$ & $1,80 \mathrm{~b}$ & $4,60 \mathrm{~b}$ & $54,50 \mathrm{~b}$ \\
\hline $\begin{array}{l}\text { Dolomítico } \\
\text { Calcinado }\end{array}$ & 18,25 & 1,76 & $5,28 \mathrm{a}$ & 0,07 & $1,79 \mathrm{a}$ & $0,95 \mathrm{a}$ & $2,17 \mathrm{~b}$ & $2,89 a$ & $5,06 \mathrm{a}$ & $58,25 \mathrm{a}$ \\
\hline Teste F & 0,53 & 2,12 & $12,17^{*}$ & 1,64 & $8,52 * *$ & $12,75^{*}$ & $19,04^{* *}$ & $10,16^{* *}$ & $4,26^{*}$ & $22,86^{* *}$ \\
\hline D.M.S. & 3,35 & 0,21 & 0,31 & 0,03 & 0,46 & 0,23 & 0,26 & 0,70 & 0,45 & 5,47 \\
\hline \multicolumn{11}{|l|}{ Fraçōes } \\
\hline$F_{1}$ & 20,00 & 1,80 & 4,83 & 0,07 & $1,14 b$ & 0,65 & 2,64 & 1,86 & 4,59 & $40,00 \mathrm{~b}$ \\
\hline $\mathbf{F}^{2}$ & 16,60 & 1,50 & $4,91 b$ & 0,09 & 1,39 & $0,78 b$ & 2,49 & 2,32 & 4,80 & $51,50 \mathrm{a}$ \\
\hline $\mathrm{F}^{3}$ & 19,25 & 1,68 & 5,10 & 0,06 & 1,60 & 0,70 & 2,28 & 2,52 & 4,88 & $58,75 a$ \\
\hline$F^{4}$ & 19,50 & 1,79 & 5,24 & 0,08 & 1,73 & 0,88 & 2,38 & 12,68 & 5,06 & $57,75 a$ \\
\hline Teste F & 0,86 & 1,84 & 1,52 & 0,66 & 1,34 & 0,76 & 1,52 & 1,09 & 0,80 & $10,19 * *$ \\
\hline D.M.S. & 6,32 & 0,40 & 0,58 & 0,05 & 0,86 & 0,43 & 0,49 & 1,32 & 0,85 & 10,33 \\
\hline Testemunha & 21,00 & 1,50 & 4,30 & 0,08 & 0,70 & 0,20 & 3,43 & 0,99 & 4,38 & 22,00 \\
\hline $\begin{array}{l}\text { Teste FT } \\
\mathrm{x} \text { demais }\end{array}$ & 0,78 & 1,47 & $10,14^{* *}$ & 0,09 & $5,21 *$ & $10,72^{* *}$ & $26,93 * *$ & $7,03 *$ & 1,88 & $55,78 * *$ \\
\hline $\begin{array}{l}\text { Teste } \mathbf{P} \text { p/ } \\
\text { int } C \times \mathbf{F}\end{array}$ & 0,76 & 0,54 & 0,75 & 0,77 & 1,00 & 0,07 & 0,87 & 0,93 & 0,91 & 1,47 \\
\hline
\end{tabular}

Médias com letras iguais não diferem pelo Teste de Tukey a $5 \%$

* = significativo a $5 \%$

** = significativo a $1 \%$

e para as finuras, somente foram constatados efeitos para os teores de $\mathrm{Ca}$, sendo a $\mathrm{F}_{4}$ mais reativa; apesar desse tempo decorrido, o valor de V\% elevou-se somente até $54,25 \%$. SOUZA \& NEPTUNE (1979) citam que essa reação mais rápida propicia, além de maior absorção de cálcio pelas plantas, também uma maior perda por lixiviação.

O Quadro 04 apresenta os dados referentes a $4^{\mathrm{a}}$ amostragem de solo (730 dias após a calagem). Observou-se que, depois de passado esse tempo, não se constatou diferenças entre as finuras, e que a reatividade, quando comparada com a do $1^{\circ}$ ano, era bem menor. Das interações obtidas, sempre o calcário calcinado com as finuras $F_{2}$ e $F_{3}$, foi mais reativo.
No Quadro 05, encontram-se os dados de análise de folhas referentes a $1^{\circ}$ ano agrícola (88/89). O calcário calcinado elevou os teores de $\mathrm{Mg}$ e os graus de finura não tiveram efeito significativo. Para a interação calcário $x$ frações, o maior teor de proteína $\mathbf{( 1 7 , 1 1 \% )}$ foi obtido com o dolomítico calcinado versus o dolomítico $(23,39 \%)$, dentro do grau de finura $F_{2}$; o teor de $\mathbf{K}$ também foi alterado, sendo o menor de $1,15 \%$ obtido com o calcinado e o maior, $1,50 \%$ com o dolomítico e isso pode ser explicado pela competição do $\mathrm{Ca}$ com o $\mathrm{K}$ pelos sítios de absorção.

Para o $2^{\circ}$ ano agrícola $(89 / 90)$, os dados de análise de folhas encontram-se no Quadro 06 , onde se observa somente efeito para o $\mathbf{M g}$, para a testemunha 
QUADRO 3 - Valores médios obtidos para as diversas caracteristicas analisadas no solo com os respectivos testes F para a análise de variância e testes de Tukey para comparações múltiplas $\left(3^{2}\right.$ amostragem $0-20 \mathrm{~cm}$, 540 dias ap6s a aplicação dos corretivos).

\begin{tabular}{|c|c|c|c|c|c|c|c|c|c|c|}
\hline \multirow[t]{2}{*}{ Calcários } & \multirow{2}{*}{$\underset{\mu \mathrm{g} / \mathrm{ml}}{\mathbf{P}}$} & \multirow{2}{*}{$\begin{array}{r}\text { MO } \\
\%\end{array}$} & \multirow{2}{*}{$\begin{array}{c}\mathbf{p H} \\
\mathrm{CaCl}_{2} \\
0,01 \mathrm{~m}\end{array}$} & $\mathbf{K}$ & $\mathrm{Ca}$ & $\mathbf{M g}$ & $\mathbf{H}+\mathbf{A l}$ & SB & $\mathbf{T}$ & v \\
\hline & & & & \multicolumn{6}{|c|}{$\mathrm{meq} / 100 \mathrm{~cm}^{3}$} & $\%$ \\
\hline Dolomítico & 24,00 & 1,65 & $4,80 b$ & 0,09 & 1,76 & 0,79 & $2,77 a$ & 5,41 & $2,41 b$ & $48,90 \mathrm{~b}$ \\
\hline $\begin{array}{l}\text { Dolomítico } \\
\text { Calcinado }\end{array}$ & 23,38 & 1,71 & $5,09 a$ & 0,08 & 1,86 & 0,90 & 2,40 & 5,30 & $2,65 a$ & $54,25 \mathrm{a}$ \\
\hline Teste F & 0,46 & 1,65 & $11,21^{*}$ & 2,29 & 3,41 & 2,71 & $11,69 * *$ & 1,47 & 4,50 & $9,64^{* *}$ \\
\hline D.M.S. & 1,88 & 0,09 & 0,13 & 0,01 & 0,13 & 0,13 & 0,20 & 0,18 & 0,25 & 4,09 \\
\hline \multicolumn{11}{|l|}{ Fraçōes } \\
\hline$F_{1}$ & $26,00 a$ & 1,88 & $4,89 b$ & 0,10 & $1,79 \mathrm{ab}$ & 0,81 & $2,74 \mathrm{ab}$ & 5,43 & 2,70 & 49,50 \\
\hline$F^{2}$ & $25,38 a$ & 1,68 & $5,14 a$ & 0,09 & $1,99 \mathrm{a}$ & 0,90 & $2,38 b$ & 5,35 & 2,99 & 55,69 \\
\hline$F^{3}$ & $21,79 b$ & 1,56 & $5,03 \mathrm{ab}$ & 0,09 & $1,79 \mathrm{ab}$ & 0,84 & $2,50 \mathrm{ab}$ & 5,22 & 2,67 & 51,13 \\
\hline $\mathbf{F}^{*}$ & $21,63 b$ & 1,70 & $4,90 \mathrm{ab}$ & 0,08 & $1,60 \mathrm{~b}$ & 0,84 & $2,80 \mathrm{a}$ & 5,42 & 2,62 & 48,38 \\
\hline Teste F & $6,43^{* * *}$ & 0,13 & $3,44^{*}$ & 0,85 & $3,59 *$ & 0,33 & $4,24^{*}$ & 1,21 & 1,83 & 2,56 \\
\hline D.M.S. & 3,55 & 0,17 & 0,25 & 0,02 & 0,25 & 0,25 & 0,38 & 0,35 & 0,48 & 7,72 \\
\hline Testemunha & 22,00 & 1,73 & 4,5 & 0,08 & 1,35 & 0,58 & 3,20 & 5,25 & 2,05 & 38,75 \\
\hline $\begin{array}{l}\text { Teste FT } \\
\mathrm{x} \text { demais }\end{array}$ & 1,51 & 0,51 & $16,57^{* *}$ & 2,29 & $23,32 * *$ & $7,88 * *$ & $16,87^{* *}$ & 0,61 & $13,90^{* *}$ & $17,23 * *$ \\
\hline $\begin{array}{l}\text { Teste P p } \\
\text { int } C \times \mathbf{F}\end{array}$ & $3,60^{*}$ & 0,35 & 1,36 & 1,75 & 3,94 & 0,43 & 3,41 & 0,38 & 2,21 & $3,21^{*}$ \\
\hline
\end{tabular}

Médias com letras iguais não diferem pelo Teste de Tukey a $5 \%$

* = significativo a $5 \%$

$* *$ = significativo a $1 \%$ 
QUADRO 4 - Valores médios obtidos para as diversas características analisadas no solo com os respectivos testes $F$ para a análise de variância e testes de Tukey para comparaçōes múltiplas (4* amostragem $0-20 \mathrm{~cm}, 730$ dias após a aplicaçāo dos corretivos).

\begin{tabular}{|c|c|c|c|c|c|c|c|c|c|c|}
\hline \multirow[t]{2}{*}{ Calcários } & \multirow{2}{*}{$\begin{array}{c}P \\
\mu \mathrm{g} / \mathrm{ml}\end{array}$} & \multirow{2}{*}{$\begin{array}{r}\text { MO } \\
\%\end{array}$} & \multirow{2}{*}{$\begin{array}{c}\mathrm{pH} \\
\mathrm{CaCl}_{2} \\
0,01 \mathrm{~m}\end{array}$} & $\mathbf{K}$ & $\mathrm{Ca}$ & $\mathbf{M g}$ & $\mathbf{H}+\mathbf{A l}$ & SB & $\mathbf{T}$ & \multirow{2}{*}{$\begin{array}{l}\mathrm{V} \\
\%\end{array}$} \\
\hline & & & & \multicolumn{6}{|c|}{$\mathrm{meq} / 100 \mathrm{~cm}^{3}$} & \\
\hline Dolomitico & 38,56 & 1,56 & 4,91 & 0,15 & 1,62 & 0,78 & 3,28 & 2,55 & 5,82 & 43,59 \\
\hline $\begin{array}{l}\text { Dolomítico } \\
\text { Calcinado }\end{array}$ & 44,00 & 1,40 & 5,02 & 0,13 & 1,88 & 0,82 & 3,20 & 2,82 & 5,85 & 47,69 \\
\hline Teste F & 1,46 & 1,13 & 0,88 & 4,03 & 2,08 & 0,17 & 1,77 & 1,19 & 0,02 & 1,35 \\
\hline D.M.S. & 9,25 & 0,84 & 0,23 & 0,02 & 0,37 & 0,19 & 0,39 & 0,52 & 0,35 & 7,07 \\
\hline \multicolumn{11}{|l|}{ Frações } \\
\hline $\mathbf{F}_{1}$ & $37,00 \mathrm{~b}$ & 1,44 & 5,01 & 0,14 & 1,93 & 0,85 & 3,09 & 2,91 & $6, \infty 0$ & 48,13 \\
\hline$F^{2}$ & $56,75 a$ & 1,53 & 5,00 & 0,14 & 1,81 & 0,79 & 3,28 & 2,74 & 5,92 & 46,00 \\
\hline $\mathbf{F}^{3}$ & $39,00 \mathrm{~b}$ & 1,6 & 4,85 & 0,12 & 1,63 & 0,40 & 3,24 & 2,48 & 5,72 & 43,13 \\
\hline $\mathbf{F}^{4}$ & $32,30 \mathrm{~b}$ & 1,55 & 5,00 & 0,15 & 1,63 & 0,83 & 3,20 & 2,60 & 5,70 & 45,50 \\
\hline Teste F & $5,61 * *$ & 1,50 & 0,47 & 1,67 & 0,60 & 0,28 & 0,14 & 0,53 & 0,73 & 0,06 \\
\hline D.M.S. & 17,45 & 0,16 & 0,44 & 0,04 & 0,69 & 0,36 & 0,73 & 0,08 & 0,66 & 11,34 \\
\hline Testemunha & 32,25 & 1,58 & 4,65 & 0,13 & 0,13 & 0,55 & 3,63 & 2,00 & 5,63 & 35,75 \\
\hline $\begin{array}{l}\text { Teste } F T \\
x \text { demais }\end{array}$ & 1,78 & 0,00 & 3,47 & 0,45 & 2,50 & 0,27 & 2,84 & 3,24 & 0,61 & 3,70 \\
\hline $\begin{array}{l}\text { Teste P p' } \\
\text { int } C \times \mathbf{F}\end{array}$ & $3,02 *$ & 1,50 & 0,23 & 1,59 & 1,11 & 0,52 & 0,63 & 0,76 & 2,68 & 0,45 \\
\hline
\end{tabular}

Médias com letras iguais não diferem pelo Teste de Tukey a $5 \%$

* = significativo a $5 \%$

** = significativo a $1 \%$ 
QUADRO 5 - Valores médios obtidos para as diversas características analisadas no solo com os respectivos teste F para a análise de variância e testes de Tukey para comparaçōes múltiplas (florescimento) (1 ano agrícola 88/89).

\begin{tabular}{|c|c|c|c|c|c|c|}
\hline Calcários & $\mathbf{N}$ & $\mathbf{P}$ & $\mathrm{Ca}$ & $\mathbf{M g}$ & $\mathbf{C u}$ & $\mathbf{Z n}$ \\
\hline \multicolumn{4}{|c|}{$\%$} & \multicolumn{3}{|c|}{ ppm } \\
\hline Dolomítico & 4,13 & 0,28 & 1,13 & $0,40 b$ & 30,19 & 55,69 \\
\hline $\begin{array}{l}\text { Dolomítico } \\
\text { Calcinado }\end{array}$ & $4,16 \mathrm{a}$ & 0,28 & 1,19 & $0,51 \mathrm{a}$ & 35,56 & 31,38 \\
\hline Teste F & 0,04 & 0,32 & 0,72 & $14,47^{* *}$ & 2,70 & 2,46 \\
\hline D.M.S. & 0,27 & 0,01 & 0,14 & 0,06 & 6,72 & 5,64 \\
\hline \multicolumn{7}{|l|}{ Frações } \\
\hline $\mathbf{F}_{1}$ & 4,13 & 0,28 & 1,11 & 0,44 & 28,75 & 53,63 \\
\hline$F^{2}$ & 4,04 & 0,27 & 1,13 & 0,44 & 37,63 & 55,38 \\
\hline $\mathbf{F}^{3}$ & 4,14 & 0,29 & 1,20 & 0,45 & 36,63 & 51,13 \\
\hline $\mathbf{F}^{4}$ & 4,27 & 0,29 & 1,21 & 0,49 & 25,50 & 54,00 \\
\hline Teste F & 0,50 & 2,89 & 0,54 & 0,62 & 2,27 & 0,42 \\
\hline D.M.S. & 0,51 & 0,03 & 0,26 & 0,11 & 12,67 & 10,64 \\
\hline Testemunha & 4,65 & 0,28 & 1,19 & 0,40 & 29,00 & 50,25 \\
\hline $\begin{array}{l}\text { Teste FT } \\
\mathrm{x} \text { demais }\end{array}$ & $6,72^{*}$ & 0,02 & 0,10 & 1,09 & 0,62 & 0,63 \\
\hline $\begin{array}{l}\text { Teste } P \text { p int } \\
x \text { F }\end{array}$ & 2,29 & 0,10 & 1,31 & 1,25 & 0,77 & 0,45 \\
\hline
\end{tabular}

Médias com letras iguais não diferem pelo teste de Tukey a $5 \%$

* = significativo a $5 \%$

** = significativo a $1 \%$ 
QUADRO 6 - Valores médios obtidos para as diversas características analisadas no solo com os respectivos testes $F$ para a análise de variância e testes de Tukey para comparações múltiplas (florescimento), (2 ano agrícola 89/90).

\begin{tabular}{|c|c|c|c|c|c|c|c|c|}
\hline \multirow[t]{2}{*}{ Calcários } & $\mathbf{N}$ & Proteína & $\mathbf{P}$ & $\mathbf{K}$ & $\mathrm{Ca}$ & $\mathbf{M g}$ & $\mathrm{Cu}$ & $\mathbf{Z n}_{\mathbf{n}}$ \\
\hline & \multicolumn{4}{|c|}{$\%$} & & & \multicolumn{2}{|c|}{ ppm } \\
\hline Dolomítico & 3,09 & 19,31 & 0,25 & 1,18 & 1,92 & 0,62 & 52,00 & 78,31 \\
\hline $\begin{array}{l}\text { Dolomítico } \\
\text { Calcinado }\end{array}$ & 3,04 & 18,97 & 0,25 & 1,17 & 1,90 & 0,67 & 52,38 & 79,00 \\
\hline Teste F & 0,39 & 0,32 & 0,04 & 0,01 & 0,04 & 1,16 & 0,02 & 0,19 \\
\hline D.M.S. & 0,19 & 1,21 & 0,01 & 0,14 & 0,19 & 0,08 & 4,91 & 3,24 \\
\hline \multicolumn{9}{|l|}{ Frações } \\
\hline $\mathbf{F}_{1}$ & 3,01 & 18,78 & 0,24 & 1,10 & 2,02 & 0,65 & 51,25 & 78,13 \\
\hline $\mathbf{F}^{2}$ & 3,06 & 19,15 & 0,25 & 1,08 & 1,88 & 0,67 & 53,63 & 77,38 \\
\hline $\mathbf{F}^{3}$ & 2,98 & 18,53 & 0,26 & 1,18 & 1,09 & 0,62 & 52,13 & 80,63 \\
\hline$F^{*}$ & 3,22 & 20,10 & 0,26 & 1,33 & 1,84 & 0,63 & 51,75 & 78,50 \\
\hline Teste F & 1,29 & 1,37 & 1,61 & 3,02 & 0,72 & 0,33 & 0,18 & 0,78 \\
\hline D.M.S. & 0,37 & 2,28 & 0,02 & 0,26 & 0,05 & 0,16 & 9,26 & 6,10 \\
\hline Testemunha & 3,45 & 21,05 & 0,25 & 1,11 & 1,82 & 0,48 & 45,00 & 75,50 \\
\hline Teste FT $\mathrm{x}$ demais & $7,16^{*}$ & $4,63 *$ & 0,21 & 0,43 & 0,45 & $6,98^{*}$ & 4,01 & 1,78 \\
\hline Teste $P$ p/ int $C \times F$ & 0,73 & 0,68 & 2,13 & 2,38 & 0,28 & 0,42 & 1,01 & 0,32 \\
\hline
\end{tabular}

Médias com letras iguais não diferem pelo teste de Tukey a $5 \%$

* = significativo a $5 \%$

** = significativo a $1 \%$ 
QUADRO 7 - Valores médios obtidos para as diversas caracteríticas analizadas nos gráos com os respectivos testes $\mathrm{F}$ para a ańlise de variância e testes de Tukey para comparações múltiplas ( $1^{\circ}$ ano agrícola $\left.88 / 89\right)$.

\begin{tabular}{|c|c|c|c|c|c|c|c|c|c|}
\hline \multirow[t]{2}{*}{ Calcários } & \multirow{2}{*}{$\begin{array}{c}\text { Produção } \\
\mathbf{K g} / \mathbf{h a}\end{array}$} & $\mathbf{N}$ & Proteína & $\mathbf{P}$ & $\mathbf{K}$ & $\mathrm{Ca}$ & $\mathbf{M g}$ & $\mathbf{C u}$ & $\mathbf{Z n}$ \\
\hline & & \multicolumn{3}{|c|}{$\%$} & & & \multicolumn{3}{|c|}{ ppm } \\
\hline Dolomítico & $211,92 \mathrm{~b}$ & 6,09 & 38,06 & 0,54 & 1,69 & 0,30 & 0,27 & $29,13 a$ & 37,00 \\
\hline $\begin{array}{l}\text { Dolomítico } \\
\text { Calcinado }\end{array}$ & $2414,04 a$ & 5,99 & 37,46 & 0,54 & 1,66 & 0,29 & 0,27 & $24,25 b$ & 34,44 \\
\hline Teste F & $7,25 *$ & 1,25 & 1,25 & 0,02 & 1,44 & 1,59 & 0,13 & $4,36 *$ & 3,04 \\
\hline D.M.S. & 227,34 & 0,18 & 1,12 & 0,02 & 0,06 & 0,02 & 0,01 & 4,79 & 3,02 \\
\hline \multicolumn{10}{|l|}{ Fraçס̄es } \\
\hline $\mathbf{F}_{1}$ & 2104,40 & 6,09 & 38,07 & 0,54 & 1,69 & 0,28 & 0,27 & 23,38 & 36,38 \\
\hline$F^{2}$ & 2002,07 & 6,14 & 38,37 & 0,54 & 1,66 & 0,31 & 0,27 & 28,25 & 35,38 \\
\hline$F^{3}$ & 2391,48 & 6,00 & 37,51 & 0,52 & 1,66 & 0,31 & 0,27 & 26,50 & 35,43 \\
\hline $\mathbf{F}^{*}$ & 2361,96 & 5,93 & 37,09 & 0,55 & 1,69 & 0,30 & 0,28 & 28,63 & 35,50 \\
\hline Teste F & 1,76 & 1,11 & 1,11 & 1,03 & 0,29 & 2,03 & 0,76 & 1,05 & 0,09 \\
\hline D.M.S. & 428,79 & 0,34 & 2,11 & 0,04 & 0,12 & 0,04 & 0,01 & 9,04 & 5,49 \\
\hline Testemunha & 1365,11 & 5,39 & 33,72 & 0,57 & 1,66 & 0,31 & 0,22 & 22,75 & 33,00 \\
\hline $\begin{array}{l}\text { Teste FT } \\
\mathbf{X} \text { demais }\end{array}$ & $29,35^{* *}$ & 24,48 ** & $24,49 * *$ & 3,77 & 0,66 & 1,18 & $113,55 * *$ & 1,27 & 1,51 \\
\hline $\begin{array}{l}\text { Teste } \mathbf{P} \text { p' } \\
\text { int } \mathbf{C} \times \mathbf{F}\end{array}$ & 0,26 & 0,56 & 0,55 & 0,37 & 0,20 & 0,46 & 2,40 & 1,27 & 0,21 \\
\hline
\end{tabular}

Médias com letras iguais não diferem pelo teste de Tukey a $5 \%$

* = significativo a $5 \%$

$* *$ = significativo a $1 \%$ 
QUADRO 8 - Valores médios obtidos para as diversas características analisadas nos grãos com os respectivos testes $F$ para a ańlise de variância e testes de Tukey para comparaçōes múltiplas (2 ano agrícola 89/90).

\begin{tabular}{|c|c|c|c|c|c|c|c|c|c|c|c|}
\hline \multirow[t]{2}{*}{ Calctrios } & \multirow{2}{*}{$\begin{array}{c}\text { Produção } \\
\text { Kg/ha }\end{array}$} & $\mathbf{N}$ & Protefna & $\mathbf{P}$ & $\mathbf{K}$ & $\mathrm{Ca}$ & $\mathbf{M g}$ & $\mathrm{Cu}$ & $\mathbf{M n}$ & $\mathbf{F e}$ & $\mathbf{Z n}$ \\
\hline & & & \multicolumn{4}{|c|}{$\%$} & \multicolumn{5}{|c|}{ ppm } \\
\hline Dolomftico & $1.821,03$ & $5,76 b$ & 36,03 & $0,53 b$ & 1,79 & 0,40 & 0,26 & 11,75 & 42,25 & 114,88 & 42,38 \\
\hline $\begin{array}{l}\text { Dolomítico } \\
\text { Calcinado }\end{array}$ & $2.004,72$ & $5,95 a$ & $37,16 \mathrm{a}$ & 0,54 & 1,78 & $\mathbf{0 , 4 0}$ & 0,26 & 11,50 & 37,13 & 121,25 & 41,56 \\
\hline Teste F & 3,80 & $4,90^{*}$ & $4,90^{*}$ & 0,79 & 0,04 & 0,07 & 0,03 & 0,70 & 2,98 & 0,47 & 1,5 \\
\hline D.M.S. & 103,53 & 0,17 & 1,05 & 0,03 & 0,05 & 0,02 & 0,02 & 0,61 & 6,10 & 15,96 & 1,35 \\
\hline \multicolumn{12}{|l|}{ Frações } \\
\hline $\mathbf{F}_{1}$ & $2.045,51$ & 5,76 & 35,98 & 0,53 & 1,79 & 0,42 & 0,25 & 11,75 & 39,50 & 119,00 & 42,38 \\
\hline$F^{2}$ & $1.759,10$ & 5,89 & 36,78 & 0,54 & 1,81 & 0,41 & 0,26 & 11,88 & 40,50 & 116,50 & 42,38 \\
\hline$F^{3}$ & $2.034,84$ & 5,87 & 36,71 & 0,53 & 1,76 & 0,39 & 0,25 & 10,88 & 39,25 & 120,50 & 40,63 \\
\hline$F^{*}$ & $1.811,08$ & 5,91 & 36,91 & 0,54 & 1,78 & 0,39 & 0,27 & 12,00 & 39,50 & 120,25 & 40,63 \\
\hline Teste F & 2,47 & 0,48 & 0,47 & 0,33 & 0,00 & 1,04 & 0,00 & 2,92 & 0,03 & 0,04 & 1,87 \\
\hline D.M.S. & 365,02 & 0,32 & 1,96 & 0,05 & 0,10 & 0,04 & 0,03 & 1,16 & 11,50 & 30,10 & 2,54 \\
\hline Testemunha & $1.640,31$ & 5,76 & 36,02 & 0,54 & 1,00 & 0,39 & 0,25 & 11.75 & 58,00 & 126,50 & 42,00 \\
\hline $\begin{array}{l}\text { Teste FT } \\
\text { x demais }\end{array}$ & 3,72 & 0,57 & 0,56 & 0,04 & 0,12 & 0,98 & 0,64 & 0,00 & $16,90^{*}$ & 8,52 & 0,00 \\
\hline $\begin{array}{l}\text { Teste } P \text { p/ } \\
\text { int } C \times F\end{array}$ & 1,81 & 0,61 & 0,61 & 0,96 & 1,07 & 1,45 & 0,59 & 2,92 & 0,42 & 11,53 & 0,49 \\
\hline
\end{tabular}

Médias com letras iguais nāo diferem pelo teste de Tukey a $5 \%$

* = significativo a $5 \%$

** = significativo a $1 \%$

versus tratamentos.

No Quadro 07 constam os dados das produções de grãos e suas análises químicas para o ano agrícola de 88/89.

Observa-se que somente os calcários afetaram a produção de grãos e o teor de $\mathrm{Cu}$ nos grãos, sendo que a maior produção foi obtida com o calcinado $\mathbf{2 . 4 1 4}$ $\mathrm{kg} / \mathrm{ha}$ ), bem como o menor teor de $\mathrm{Fe}$, o que é explicado pela diminuição da solubilidade desse micronutriente em valores $\mathrm{pH}$ maiores; para o $\mathrm{Zn}$, a única diferença, dentro do dolomítico, foi para as finuras $F_{1}\left(52,5\right.$ ppm) e $F_{3}(40,25 \mathrm{ppm})$.

No Quadro 8 são apresentados os dados de produção e de análises químicas dos grãos do $2^{\circ}$ ano agrícola (89/90); diferentemente do $1^{\circ}$ ano, houve efeito significativo na elevação do teor de proteínas, propiciado pelo calcinado, bem como uma diminuição nos teores de $\mathrm{Mn}$, quando os tratamentos foram comparados com a testemunha.

\section{CONCLUSÕES}

Conclui-se que no $1^{\circ}$ ano agrícola $(88 / 89)$ o calcário dolomítico calcinado foi mais reativo que o dolomítico, melhorando as propriedades químicas do solo e sempre tendo os efeitos melhores para as granulometrias mais finas; para a produção de grãos, houve um aumento de $14 \%$. No $2^{\circ}$ ano $(89 / 90)$ as reatividades dos calcários tenderam a se igualar e as finuras mais grosseiras, a melhorar seus efeitos não houve efeito na produção de grãos; de uma maneira global, não houve efeitos de calcários e de finuras em alterações químicas foliares e de grãos, a não ser para o $\mathbf{M g}$. 


\section{REFERENCIAS BIBLIOGRÁFICAS}

BATAGLIA, O.C.; FURLANI, A.M.C.; TEIXEIRA, S.P.F.; FURLANI, P.R.; GALLO, J.R. Métodos de análise química de plantas. Campinas, Instituto Agronômico, 1983. 48p. (Boletim Técnico, 78).

BELLINGIERI, P.A. Avaliação em laboratório da eficiência relativa de diferentes frações granulométricas de calcários, na neutralização da acidez do solo. Piracicaba,SP, ESALQ/USP. 1983. 99p. Tese de Doutorado.

FERREIRA, M.E.; CRUZ, M.C.P.; FERREIRA JUNIOR, M.E. Avaliação da fertilidade empregando o sistema IAC de análise de solo. Jaboticabal, FCAV, 1990. 94p.

HOYERT, J.H. \& AXLEY, J.H. Influence of liming materials on $\mathrm{pH}$ values of six Maryland soils. Soil Science, New Jersey, 73:61-9, 1952.

MEYER, T.A. \& VOLK, N.W. Effect of particle size of limestone on reaction, exchangeable cations and plant growth. Soil Science, New Jersey, 97:11929, 1967.

SHAW, W.M. \& ROBINSON, B. Reaction efficiences of liming as indicated by lisimeter leachate composition. Soil Science, New Jersey, 89:209-18, 1960.

SOUZA, E.A. \& NEPTUNE, A.M.L. Efeitos da granulometria de calcário dolomítico sobre as propriedades químicas de um Latossolo. Revista Brasileira de Ciência do Solo, Campinas, 3:1205, 1979.

TEDESCO, M.J. \& ANGHINONI, I. Efetividade da superficie específica de partículas do calcário na correção da acidez do solo. Santa Maria,RS. UFRG, 1980. 19p.

Trabalho entregue para publicação em 30.04.91

Trabalho aprovado para publicação $\mathrm{em}$ 01.08.91 